\title{
Time spent watching television impacts on BMI in youth with obesity, but only in those with shortest sleep duration.
}

\section{Title Page, original article}

\section{Time spent watching television impacts on BMI in youth with obesity, but only in those with shortest sleep duration.}

\begin{abstract}
Daniel M Golshevsky (FRACP) $)^{1,2}$, Costan Magnussen (PhD) ${ }^{4,5}$, Markus Juonala $(\mathrm{PhD})^{3,6,7}$, Kung-Ting Kao (MBChB) $)^{1,2,3}$, Brooke E Harcourt ${ }^{1,2,3}$, Matthew A Sabin (PhD) ${ }^{1,2,3}$

${ }^{1}$ Royal Children's Hospital, Victoria, Australia; ${ }^{2}$ University of Melbourne, Victoria, Australia; ${ }^{3}$ Murdoch Childrens Research Institute, Victoria, Australia; ${ }^{4}$ Menzies Institute for Medical Research, University of Tasmania, Hobart, Australia; ${ }^{5}$ Research Centre of Applied and Preventive Cardiovascular Medicine, University of Turku, Turku, Finland; ${ }^{6}$ Department of Medicine, University of Turku, Finland; ${ }^{7}$ Division of Medicine, Turku University Central Hospital, Finland.
\end{abstract}

Keywords: overweight, obesity, childhood, screen time, sleep, physical activity, exercise, diet

Disclosure Statement: This was not an industry supported study. The authors have indicated no conflicts of interest. Written informed consent was obtained from all participants for data collection. The study has institutional ethics approval.

Running Title: TV and sleep in youth with obesity.

Corresponding author: A/Prof Matthew Sabin, Centre for Hormone Research, Murdoch Childrens Research Institute, Flemington Road, Parkville, Victoria 3052, Australia. Tel: + 61 39345 5951. Fax: +61 39345 6240. E-mail: matthew.sabin@mcri.edu.au

Acknowledgements: The authors sincerely thank the parents and children participating in the COBRA study, as well as the research team that continue to grow the COBRA repository. MJ was funded by Paulo Foundation, Paavo Nurmi Foundation, Finnish Cardiovascular Research Foundation, Finnish Medical Foundation, Maud Kuistila Foundation, Sigrid Juselius Foundation and Federal Research grants to Turku University Hospital.

Keywords: overweight, obesity, childhood, screen time, sleep, physical activity, exercise, diet

Disclosure Statement: This was not an industry supported study. The authors have indicated no conflicts of interest. Written informed consent was obtained from all participants for data collection. The study has institutional ethics approval.

This is the author manuscript accepted for publication and has undergone full peer review but has not been through the copyediting, typesetting, pagination and proofreading process, which may lead to differences between this version and the Version of Record. Please cite this article as doi: $10.1111 /$ jpc.14711

This article is protected by copyright. All rights reserved. 
Running Title: TV and sleep in youth with obesity.

This article is protected by copyright. All rights reserved. 


\begin{abstract}
Aim: To determine the interplay between sleep and sedentary behaviours on body mass index (BMI) in children with obesity.

Methods: Cross-sectional study of 343 children with obesity aged 4-17 years, from a Tertiary care weight management clinic in Melbourne, Victoria, Australia. Multifaceted data relating to activity and sleep from child and parent questionnaires analysed with anthropometric data collected during routine clinical care. Associations between sleep duration and activity measures were examined via regression models with adjustment for potential confounders.
\end{abstract}

Results: Higher BMI was associated with more hours spent watching television ( $\mathrm{p}=0.04)$, as well as less reported enjoyment of physical activity $(\mathrm{p}=0.005)$ and less time spent in organised sport activity $(\mathrm{p}=0.005)$. Higher $\mathrm{BMI}$ was also associated with higher levels of obstructive sleep apnoea ( $\mathrm{p}=0.002)$. Less time in bed was associated with higher levels of BMI $(p=0.03)$ but analysis by sex revealed this association to only hold for males. In the whole group, a significant television and sleep interaction was seen, such that increasing TV watching was associated with higher BMI, but only in those with shortest sleep duration.

Conclusions: Both poor sleep and increasing screen time (including television viewing, smart-phone use, internet use or video-gaming) appear to impact BMI in children with obesity, with a particular detrimental effect of TV viewing in those who sleep less. Efforts to improve sleep time and quality in children may minimise negative effects of ST on increasing BMI and should be included in public health strategies to combat obesity in childhood.

\title{
Learning Points
}

What is already known on this topic: Inadequate sleep, high caloric intake, reduced physical activity and screen time are associated with higher BMI in a general paediatric population.

What this paper adds: This paper focuses on children with overweight and obesity as a cohort and differentiates between types of screen time (ST) used, finding no difference in impact on BMI. These data also reveal a sex-dependent difference in that high ST and low physical activity (PA) are associated with a higher BMI in females, but only adequate sleep is statistically significant for males. Across sexes, high ST levels related to BMI only in those subjects who reported less sleep. 


\section{Introduction}

Obesity is a worldwide pandemic and its prevalence in Australia is one of the highest in the developed world ${ }^{1}$. Paediatric obesity is a significant concern with current data suggesting that one in four children is obese ${ }^{2}$, with early obesity tracking strongly across the life-course, predisposing to metabolic disease later in life ${ }^{345}$.

With an estimated annual cost of \$21billion in Australia, identifying the biological and environmental cues for obesity is a national health and economic priority ${ }^{6}$. Current literature describes a predisposing genetic susceptibility, interacting with general environmental exposures $^{78}$. This mechanism provides health promotion targets at a population level, prompting public health strategies that often target diet, sedentary activity and screen time (ST, which includes television viewing, computer gaming and smart-phone and computer usage $)^{9}$.

Despite strong data supporting theoretical measures to target these factors, current strategies for the prevention and treatment of childhood obesity have arguably failed and other factors are now being examined in more detail ${ }^{10}$. There is a growing body of evidence linking poor sleep quality and duration to obesity ${ }^{11}{ }^{12}$. Sufficient sleep is essential to overall health, with sleep inadequacy triggering hormonal, metabolic and behavioural cascades that increase dietary energy intake and decrease energy expenditure ${ }^{13} 1415$. Meta-analyses confirm that poor sleep quality and duration is associated with higher positive energy balance, culminating in higher body mass indices along with several other cardio-metabolic risk factors ${ }^{16} 1718$.

There are also strong associations between ST and reduced sleep, with some studies finding the actual time of going to bed more relevant to BMI than overall sleep duration ${ }^{19}$. Beyond displacing normal sleep, ST also affects arousal and upsets circadian rhythms due to light exposure $^{20}$. Prolonged video game use has also been shown to decrease objective sleep efficiency, total sleep time and subjective sleep quality ${ }^{21}{ }^{22}$. Conversely, regular physical activity (PA) has been linked with decreased insomnia symptoms and two studies have demonstrated altered food preferences following sleep disruption 232425 .

It is not currently known how sleep and ST interact with the degree of obesity in a paediatric population with obesity. It is possible that public health measures to reduce ST in children have targeted too diverse a population. However, interventions aimed at reducing ST have shown the greatest BMI changes in the upper tail of BMI distribution only, without a similar effect in the lower tail ${ }^{26}$. Therefore, our aim was to study a clinical cohort of obese children $(n=343,4-17$ years) to determine the effect of sleep and ST on BMI. 


\section{Methods}

\section{Sample}

Overweight (above $85^{\text {th }}$ centile cut-off of US-derived data produced by the Center for Disease Control and Prevention) and obese (above $95^{\text {th }}$ centile) children and adolescents (aged up to 17.99 years) referred to our hospital weight management service were approached for enrolment, through the Childhood Overweight BioRepository of Australia (COBRA) ${ }^{27}$.

\section{Questionnaires}

Results from validated and standardised questionnaires from parents and patients (aged 11 years and above) relating to environment and anthropometry were pooled with data from clinical examination and medical records. For children aged under 11 years, questionnaires are from parents only. Participants were asked how many hours per week they play outdoors, watch TV, play on computers or play video games. Participants also estimated the total amount of sedentary hours. They were asked on how many days per week their family: eat in front of a TV, watch TV in their own room, participate in organised sports and walk to school. By asking the time they usually go to bed and wake up both on weekdays and weekends, the mean amount of time in bed per night was evaluated. Participants also answered questions regarding technology in the bedroom (TV, computer, etc) and how much they enjoyed physical activity (scale $0-3$ ). These are described in Table 1.

\section{Anthropometry and clinical data}

The anthropometric and clinical data collection included height, weight and blood pressure. Medical records were reviewed for information relating to the presence of weight-related comorbidities, including obstructive sleep apnoea.

\section{Sleep Assessment}

Self-reporting of sleep duration agrees closely with quantitative actigraphy ${ }^{28}{ }^{29}$. Parent and child reporting of sleep habits was used, including bedtimes and sleep duration. Although sleep requirements differ across the lifespan, short sleep duration was classified as less than 6 hours, to capture all age-groups, in accordance with existing literature ${ }^{30}$.

\section{Statistical analyses}

To examine the associations between study variables and BMI, we first performed age- and sex-adjusted regression analyses separately for each variable. Then, to examine which variables independently associated with BMI, we performed manual backward stepwise multivariable regression analyses. The final model included those variables with $\mathrm{P}<0.05$. In addition, age and sex were forced to final models. There was a strong correlation between some of the explanatory variables (e.g. $r=0.57$ between total sedentary hours and hours watching TV). Therefore, to avoid any possible bias due to collinearity, stepwise multivariable modelling was used to evaluate the independent correlates of BMI. As the cohort comprised both boys and girls aged 4-17 years, we performed interaction analyses with logistic regression to test whether the effects of risk factors differ by age or activity, sex*enjoy physical activity and sex*hours watching TV per week interaction terms. Additionally, the multivariable analyses were performed separately for both sexes and 2 different age groups (4-12 years and 13-17 years). Finally, we analysed the association of our primary interest variable, TV watching time on BMI according to tertiles of total time in 
bed/week $\left(0-33^{\text {rd }}\right.$ percentile, $34-67^{\text {th }}$ percentile and $67-100^{\text {th }}$ percentile) with linear regression modelling. 


\section{Results}

A total of 343 subjects with obesity (aged 4-17 years) were included in this study. Subject characteristics are shown in Table 2. 20.6\% of subjects had documented obstructive sleep apnoea and there was a mean 10 hours (SD 2.3h) spent in bed each night. Approximately one third of subjects reported no technology in the bedroom.

Table 3 demonstrates age- and sex-adjusted linear associations between study variables and BMI. Those with high levels of PA enjoyment had lower BMIs $(p=0.004)$ and those with more organised sporting activities also had lower BMIs $(p<0.0001)$. Those with higher BMI watched more TV ( $p=0.02)$, had more sedentary hours $(p=0.02)$ and spent less time in bed $(p=0.02)$. Obstructive sleep apnoea was associated with a higher BMI $(p<0.001)$.

Table 4 shows the multivariate analyses, demonstrating that in total, enjoying PA ( $p=0.005$ ) and having organised sports activities $(p=0.005)$ were associated with a lower BMI, whilst more sedentary activities were associated with a higher BMI $(p=0.01)$. Females who walked to school $(p<0.001)$ and enjoyed PA $(p<0.001)$ had a lower BMI, whilst females who were older $(p<0.001)$, watched more TV $(p<0.001)$ and seldom walked to school $(p<0.001)$ had a higher BMI. There was a significant sex difference, in that only sleep $(p=0.007)$ and older age $(p<0.001)$ appeared significant for higher BMI in males.

In the stepwise multivariate model among subjects aged up to 12 years, obstructive sleep apnoea was directly associated with higher BMI and organized sports activity inversely associated with higher BMI. In a similar approach among those aged 13 years or more, obstructive sleep apnoea and TV watching in own room were directly associated with higher BMI and enjoyment of physical activity and walking to school inversely associated with a higher BMI.

Figure 1 illustrates the combined effects of bedtime and TV viewing time on BMI. There was a significant interaction in a logistic regression model $(p<0.001)$. In subsequent analyses stratified by bedtime tertiles, increased TV viewing was associated with a higher BMI in those with the shortest time spent in bed. Contrary to this, if there was adequate sleep (those in the third tertile), TV viewing did not impact on BMI. 


\section{Discussion}

This study demonstrates that in a cohort of overweight and obese children and adolescents, those enjoying PA and engaging in organised sports were less likely to be severely obese. Females who were older, watched more TV and seldom walked to school were generally more severely obese, whereas more obese males tended to be older and sleep less. An interesting and unexpected finding was that although both sleep and TV viewing impact on BMI in children with obesity, there appeared to be a particular detrimental effect of excess $\mathrm{ST}$ in those with inadequate sleep.

This study differs from existing literature with a specific focus on the upper tail of the BMI distribution as well as differentiating between types of ST used. These data also reveal a sexdependent difference in that high ST and low PA are associated with a higher BMI in females, but only inadequate sleep is associated with a higher BMI in males. Across sexes, high ST levels are only related to higher BMI in those subjects who reported less sleep. Several mechanisms have been postulated, linking sleep duration with obesity ${ }^{31}$. Conceptualised as a chronic, low-grade, inflammatory state, obesity is characterised by increased circulating inflammatory markers ${ }^{32}$. Animal models confirm that poor sleep increases nicotinamide adenine dinucleotide phosphate (NADPH) activity in visceral white adipose tissue (VWAT) ${ }^{33}$, producing adipose progenitors that lead to obesity and insulin resistance in sleep-deprived mice ${ }^{34} 35$.

There is a mounting body of evidence to support the importance of sleep in obesity prevention and treatment but as yet not enough to provide consensus statements ${ }^{36}$. Sleep may affect several obesogenic risk factors, including diet and activity. Inadequate sleep alters food preferences towards a greater proportion of energy from fat and lower proportion from carbohydrates, as well as greater energy intake in the early morning (5-7:00am) ${ }^{37}$. Delayed sleep onset also provides more time for eating, is associated with increased consumption of low nutritional foods ${ }^{38}$ and exposes children to more advertising ${ }^{39}$. Low PA levels is also associated with poorer quality sleep ${ }^{40}$. In addition to directly affecting obesity risk, inadequate sleep also negatively influences other obesity risk factors and is associated with poor cognition, reduced co-ordination, increased aggression, hyperactivity and metabolic dysfunction $^{41} 42$.

Obesity also predicted shorter sleep duration in those with somnipathies (including obstructive sleep apnoea, insomnia and asthma) $)^{43} 44$. Inadequate sleep further exacerbates body mass indices via less PA and more ST, possibly as somnolence reduces PA motivation and vigour ${ }^{45}$. ST affects sleep in 3 demonstrated ways, through time displacement, melatonin depression and cognitive arousal ${ }^{46}$. This study proves a causal relationship, suggesting that efforts to improve sleep in obese children may minimise the negative effects of ST on BMI. This study's strengths include large numbers, objective BMI measurement and a rigorous analytic approach in a relatively large sample of overweight and obese youth. There were some limitations; however, such as those associated with self-reported data and lack of data relating time to sleep onset. 
In summary, our analyses support the notion that efforts to improve sleep in children with obesity may minimise the deleterious effects of ST. These findings have important public health implications at a time when paediatric obesity prevalence remains high.

This article is protected by copyright. All rights reserved. 


\section{REFERENCES:}

${ }^{1} \mathrm{Ng} \mathrm{M}$, Fleming T, Robinson M, et al. Global, regional, and national prevalence of overweight and obesity in children and adults during 1980-2012: a systematic analysis for the Global Burden of Disease Study 2013. The Lancet 2014; 9945: 766-781.

${ }^{2}$ Australian Institue of Health and Welfare 2017. Impact of overweight and obesity as a risk factor for chronic conditions: Australian Burden of Disease Study. Australian Burden of Disease Study series no. 11. Cat. No. BOD 12. Canberra: AIHW.

${ }^{3}$ Parsons TJ, Power C, Logan S, Summerbell CD. Childhood predictors of adult obesity: a systematic review. Int J Obes Relat Metab Disord 1999; 23(Suppl 8): S1-107.

${ }^{4}$ Freedman DS, Khan LK, Serdula MK, Dietz WH, Srinivasan SR, Berenson GS. The relation of childhood BMI to adult adiposity: the Bogalusa heart study. Pediatrics 2005; 115:22-7.

${ }^{5}$ Dietz WH. Health consequences of obesity in youth: childhood predictors of adult disease. Pediatrics 1998, 101(3 Pt 2):518-525.

${ }^{6}$ Colagiuri S, Lee CM, Colagiu R, Magliano D, Shaw JE. The Cost of Overweight and Obesity in Australia. MJA 2010; 192: 260-264

${ }^{7}$ Lioret S, Touvier M, Dubuisson C, Dufour A, Calamassi-Tran G, Lafay L, et al. Trends in child overweight rates and energy intake in France from 1999 to 2007: relationships with socioeconomic status. Obesity (Silver Spring) 2009; 17: 1092-100.

${ }^{8}$ Wellcome Trust Case Control Consortium: Genome wide association study of 14,000 cases of seven common diseases and 3,000 shared controls. Nature 2007; 447(7145): 661-678.

${ }^{9}$ Maher C, Olds TS, Eisenmann JC, Dollman J. Screen time is more strongly associated than physical activity with overweight and obesity in 9- to 16-year-old Australians. Acta Paediatrica 2012; 101: 1170-1174.

${ }^{10}$ Wake M, Baur LA, et al. Outcomes and costs of primary care surveillance and intervention for overweight or obese children: the LEAP 2 randomised controlled trial. BMJ (Clinical research ed). 2009; 339: b3308.

${ }^{11}$ Olds T, Blunden S, Dollman J, Maher C. Day type and the relationship between weight status and sleep duration in children and adolescents. Aust N Z J Public Health. 2010; 34: 165-71.

12 Eisenman J, Ekkekakis P, Holmes M. Sleep duration and overweight among Australian children and adolescents. Acta Paediatrica. 2006; 95: 956-63.

${ }^{13}$ Shechter A, Grandner MA, St-Onge, MP. The role of sleep in the control of food intake. American Journal of Lifestyle Medicine. 2014; 8(6): 371-74.

${ }^{14}$ Olds TS; Maher CA; Matricciani L. Sleep duration or bedtime? Exploring the relationship between sleep habits and weight status and activity patterns. SLEEP 2011;34(10):1299-1307.

${ }^{15}$ Penev PD. Update on energy homeostasis and insufficient sleep. J Clin Endocrinol Metab. 2012;97:17921801.

${ }^{16}$ Patel SR. Reduced sleep as an obesity risk factor. Obes Rev. 2009;10(suppl 2):61-68.

${ }^{17}$ Meng L, Zheng Y, Hui R. The relationship of sleep duration and insomnia to risk of hypertension incidence: a meta-analysis of prospective cohort studies. Hypertens Res. 2013;36:985-995.

${ }^{18}$ Grandner MA, Chakravorty S, Perlis ML, Oliver L, Gurubhagavatula I. Habitual sleep duration associated with self-reported and objectively determined cardiometabolic risk factors. Sleep Med. 2014;15:42-50

${ }^{19}$ Calamaro CJ, Park S, Mason TB, et al. Shortened sleep duration does not predict obesity in adolescents. J Sleep Res 2010;19:559-66.

${ }^{20}$ Green A, Cohen-Zion M, Haim A, Dagan Y. Evening light exposure to computer screens disrupts human sleep, biological rhythms and attention abilities. Chronobiol Int. 2017;34(7):855-865.

${ }^{21}$ Eggermont S, Van den Bulck J. Nodding off or switching off? The use of popular media as a sleep aid in secondary-school children. J Paediatr Child Health. 2006; 42: 428-433. 
${ }^{22}$ Cain N, Gradisar M. Electronic media use and sleep in school-aged children and adolescents: a review. Sleep Med. 2010; 11: 735-742

${ }^{23}$ Chang JJ, Pien GW, Stamatakis KA, Brownson RC. Association between physical activity and insomnia symptoms in rural communities of southeastern Missouri, Tennessee and Arkansas. J Rural Health. 2013; 29(3): 239-247.

${ }^{24}$ Benedict C, Brooks SJ, O’Daly OG, et al. Acute sleep deprivation enhances the brain's response to hedonic food stimuli: an fMRI study. J Clin Endocrinol Metab. 2012;97:E443-E447.

${ }^{25}$ St-Onge MP, McReynolds A, Trivedi ZB, Roberts AL, Sy M, Hirsch J. Sleep restriction leads to increased activation of brain regions sensitive to food stimuli. Am J Clin Nutr. 2012;95:818-824.

${ }^{26}$ Mitchell JA, Rodriguez D, Schmitz KH, Audrain-McGovern J. Greater screen time is associated with adolescent obesity: a longitudinal study of the BMI distribution from ages 14 to 18. Obesity (Silver Spring). 2013; 21(3): 572-575.

${ }^{27}$ Sabin MA, et al. New directions in childhood obesity research: how a comprehensive biorepository will allow better prediction of outcomes. BMC Medical Research Methodology 2010; 10:100.

${ }^{28}$ Lauderdale D, Knutson K, Yan L, Liu K, Rathouz P. Sleep duration: how well tdo self-reports reflect objective measures: how similar are they? Epidemiology. 2008;19(6):838-845.

${ }^{29}$ Cespedes E, et al. Comparison of self-reported sleep duration with actigraphy: Resulsts from the Hispanic community health study/stud of Latinos Sueno Ancillary Study. Am J Epidemiol. 2016;183(6):561-573.

${ }^{30}$ Paruthi S, Brooks LJ, D’Ambrosio C, Hall WA, Kotagal S, Lloyd RM, Malow BA, Maski K, Nichols C, Quan SF, Rosen CL, Troester MM, Wise MS. Recommended amount of sleep for paediatric populations: a consensus statement of the American Academy of Sleep Medicine. J Clin Sleep Med. 2016;12(6):785.

${ }^{31}$ Cappuccio FP, Taggart FM, Kandala NB, et al. Meta-analysis of short sleep duration and obesity in children and adults. Sleep 2008; 31: 619-26.

32 Ellulu M, Patmiah I, Khaza'ai H, Rahmat A, Abed Y. Obesity and inflammation: the linking mechanism and the complications. Arch Med Sci. 2016;13(4):851-863.

${ }^{33}$ Khalyfa A, Wang Y, Zhang SX, Qiao Z, Abdelkarim A, Gozal D. Sleep fragmentation in mice induces nicotinamide adenine dinucleotide phosphate oxidase 2-dependent mobilization, proliferation, and differentiation of adipocyte progenitors in visceral white adipose tissue. SLEEP 2014;37(5):999-1009.

${ }^{34}$ Laposky AD, Shelton J, Bass J, Dugovic C, Perrino N, Turek FW. Altered sleep regulation in leptin-deficient mice. Am J Physiol Regul Integr Comp Physiol 2006;290:R894-903.

${ }^{35}$ Barclay JL, Husse J, Bode B, et al. Circadian desynchrony promotes metabolic disruption in a mouse model of shiftwork. PLoS One 2012; 7:e37150.

${ }^{36}$ National Health and Medical Research Council (2013) Clinical practice guidelines for the management of overweight and obesity in adults, adolescents and children in Australia. Melbourne: National Health and Medical Research Council

${ }^{37}$ Shechter A, Grandner MA, St-Onge, MP. The role of sleep in the control of food intake. American Journal of Lifestyle Medicine. 2014; 8(6): 371-74.

${ }^{38}$ Fleig D, Randler C. Association between chronotype and diet in adolescents based on food logs. Eat Behav. 2009;10:115-118.

${ }^{39}$ Powell LM, Schermbeck RM, Szczypka G, et al. Trends in the nutritional content of television food advertisements seen by children in the United States. Arch Pediatr Adolesc Med 2011; 165 (12): 1078-86.

${ }^{40}$ Boreham C, Riddoch C. The physical activity, fitness and health of children. J Sports Sci 2001: 19; 915-929.

${ }^{41}$ Medic G, Wille M, Hemels M. Short- and long-term consequences of sleep disruption. Nat Sci Sleep. 2017;9:151-161.

42 Krause A, Simon EB, Mander B, et al. The sleep-deprived human brain. Nat Rev Neurosci. 2017;18(7):404418.

${ }^{43}$ Bonsignore MR, McNicholas WT, Montserrat JM, Eckel J. Adipose tissue in obesty and obstructive sleep apnoea. Eur Resp J. 2012; 39: 746-767..

${ }^{44}$ Romero-Corral A, Caples SM, Lopez-Jimenez F, Somers V. Interactions between obesity and obstructive sleep apnea: implications for treatment. Chest. 2010;137(3):711-719.

${ }^{45}$ Magee C, Caputi P, Iverson D. Lack of sleep could increase obesity in children and too much television could be partly to blame. Acta Paediatrica 2014; 103: e27-31. 
${ }^{46}$ Carter P, Taylor B, Williams S, Taylor R. Longitudinal analysis of sleep in relation to BMI and body fat in children: the FLAME study. Br Med J. 2011; 342:1-7

Table1: Parameters collected in COBRA, * relevant to current study

\begin{tabular}{ll}
\hline Self-completed participant information & Clinical exam \\
Domain: Instrument/Source (respondent ${ }^{1}$ ) & Clinical history \\
\hline Health: Self-rated health (P, C) & Specific details relating to weight \\
Concern with weight: HopSCOTCH (P) & Other health issues \\
Help seeking: HopSCOTCH (P) & Peri natal and Past Medical History \\
Pregnancy \& birth: HopSCOTCH, LSAC, NHS (P) & Medications (past and present) \\
Early nutrition: LSAC (P) & Allergies \\
Family health history: HopSCOTCH (P) & Immunisations \\
Mental health: SDQ (P, C); Kessler 10 (P, C) & Developmental history and schooling \\
Enjoyment of physical activity (PA): LEAP(P, C) & Family history \\
Active/Sedentary time: HopSCOTCH, LSAC (P, C) & Sleep issues* \\
Targeted nutrition/PA: HopSCOTCH (P, C) & \\
Transport, biking, walking: IPAQ (P, C) & Clinical examination \\
Childcare: HopSCOTCH (P) & General appearance (dysmorphism, affect, body \\
Sleep habits: LSAC (P, C)* & proportions) \\
Neighbourhood: LSAC, ALSPAC, NEWSA(P, C) & Cardiovascular examination including blood pressure \\
Socio-demographic: Census (P) & Respiratory examination \\
Household composition: FLAME (P) & Abdominal examination \\
Nutrition: 3-day prospective food diary (P, C); ACAES (P, C) & Skin (acne, hirsutism, acanthosis nigricans, intertrigo, \\
Quality of life (QoL): PedsQL Core module (P, C); Sizing Them & striae) \\
Up (P); Sizing Me Up (C) & Pubertal assessment (method of Tanner and \\
MARCA: 24-hour PA recall & Whitehouse) \\
& Anthropometry \\
& Height (measured to nearest 0.1cm using a \\
stadiometer) & Weight \\
& Waist circumference \\
& \\
\hline
\end{tabular}

HopSCOTCH: The Shared-Care Obesity Trial in Children; LSAC: Longitudinal Study of Australian Children; NHS: National Health Survey; SDQ: Strengths and Difficulties Questionnaire; LEAP: Live Eat and Play Study; IPAQ: International Physical Activity Questionnaire; ALSPAC: Avon Longitudinal Study of Parents and Children; NEWSA: Neighbourhood Environment Walkability Scale Abbreviated; FLAME: Family Lifestyle Activity Movement and Eating; ACAES: Australian Child and Adolescent Eating Survey; PedsQL: Pediatric Quality of Life survey; MARCA: Mulitmedia Activity Recall for Children and Adolescents. 
Table 2. Characteristics of study subjects. Values are mean and Std Dev unless stated otherwise.

\begin{tabular}{lccc}
\hline Variable & N & Mean & Std Dev \\
\hline Males (\%) & 343 & 47.3 & \\
Age (years) & 343 & 12.1 & 3.2 \\
BMI (kg/m2) & 305 & 34.4 & 6.9 \\
Obstructive sleep apnoea (\%) & 340 & 20.6 & \\
Enjoy physical activity (scale 0-3) & 333 & 1.4 & 0.8 \\
No technology in bedroom (\%) & 341 & 33.5 & \\
Total sedentary hours / week & 315 & 28.6 & 30.8 \\
Hours outdoor for play / week & 216 & 11.3 & 21.1 \\
Hours watching TV / week & 293 & 20.0 & 20.6 \\
Hours on computer / week & 255 & 13.5 & 14.9 \\
Hours on video-games / week & 240 & 14.4 & 24.4
\end{tabular}


Days per week, watch TV in own room

Table 3. Age - and sex-adjusted associations with BMI

\begin{tabular}{lcl}
\hline Variable & beta \pm SE & P-value \\
\hline Obstructive sleep apnoea & $3.26 \pm 0.75$ & $<0.001$ \\
Enjoy physical activity (scale 0-3) & $-1.45 \pm 0.40$ & 0.004 \\
No technology in bedroom (\%) & $-0.42 \pm 0.72$ & 0.56 \\
Total sedentary hours / week & $0.04 \pm 0.02$ & 0.02 \\
Hours outdoor for play / week & $-0.02 \pm 0.02$ & 0.26 \\
Hours watching TV / week & $0.04 \pm 0.02$ & 0.02 \\
Hours on computer / week & $0.03 \pm 0.02$ & 0.28 \\
Hours on video-games / week & $0.01 \pm 0.02$ & 0.60 \\
Days per week, family eat at TV & $0.01 \pm 0.02$ & 0.53 \\
Days per week, watch TV in own room & $0.29 \pm 0.13$ & 0.02 \\
Days per week, organized sport activity & $-0.60 \pm 0.17$ & $<0.001$ \\
Days per week, walk to school & $-0.46 \pm 0.15$ & 0.002 \\
Bedtime (time in bed / week) & $-0.83 \pm 0.37$ & 0.02 \\
\hline
\end{tabular}

Beta \pm SE values are from linear regression analyses

Table 4. Stepwise multivariable models for BMI.

(a) total subjects ( $\mathrm{N}=\mathbf{2 6 5}$ in final model)

\begin{tabular}{llll}
\hline Variable & Beta & SE & P-value \\
\hline Male gender & -1.18 & 0.62 & 0.059 \\
Age (years) & 1.08 & 0.11 & $<.0001$ \\
Obstructive sleep apnea (no/yes) & 2.32 & 0.75 & 0.002 \\
Enjoy physical activity (scale 0-3) & -1.10 & 0.39 & 0.005 \\
Total sedentary hours per week & 0.029 & 0.012 & 0.01 \\
Hours watching TV per week & 0.037 & 0.017 & 0.04
\end{tabular}




$\begin{array}{lll}-0.41 & 0.14 & 0.005 \\ -0.80 & 0.37 & 0.03\end{array}$

(b) females ( $\mathrm{N}=156$ in final model)

\begin{tabular}{llll}
\hline Variable & Beta & SE & P-value \\
\hline Age (years) & 1.05 & 0.13 & $<0.001$ \\
Obstructive sleep apnoea (no/yes) & 3.00 & 1.07 & 0.006 \\
Enjoy physical activity (scale 0-3) & -2.06 & 0.53 & $<0.001$ \\
Total sedentary hours per week & 0.037 & 0.015 & 0.02 \\
Hours watching TV per week & 0.079 & 0.023 & $<0.001$ \\
Days per week, walk to school & -0.60 & 0.18 & $<0.001$ \\
\hline
\end{tabular}

(c) males ( $\mathrm{N}=123$ in final model)

\begin{tabular}{llll}
\hline Variable & Beta & SE & P-value \\
\hline Age (years) & 1.14 & 0.19 & $<.0001$ \\
Obstructive sleep apnoea (no/yes) & 2.40 & 0.94 & 0.01 \\
Time in bed per week & -0.11 & 0.04 & 0.007 \\
\hline
\end{tabular}

(d) Children aged 4-12 years ( $\mathrm{N}=150$ in final model)

\begin{tabular}{llll}
\hline Variable & Beta & SE & P-value \\
\hline Male gender & -0.41 & 0.65 & 0.53 \\
Age (years) & 1.35 & 0.14 & $<0.001$ \\
Obstructive sleep apnoea (no/yes) & 2.30 & 0.89 & 0.01 \\
Days per week, organized sports activity & -0.43 & 0.17 & 0.02 \\
\hline
\end{tabular}

(e) children aged 13-17 years ( $\mathrm{N}=141$ in final model)

\begin{tabular}{llll}
\hline Variable & Beta & SE & P-value \\
\hline Male gender (no/yes) & -2.12 & 1.05 & 0.04 \\
Age (years) & 1.31 & 0.38 & 0.001 \\
Obstructive sleep apnoea (no/yes) & 3.81 & 1.16 & 0.001 \\
Enjoy physical activity (scale 0-3) & -1.79 & 0.67 & 0.009 \\
Days per week, watch TV in own room & 0.59 & 0.19 & 0.002 \\
Days per week, walk to school & -0.50 & 0.22 & 0.03 \\
\hline
\end{tabular}

\section{SEE SEPARATE UPLOAD FOR FIGURE 1}

Figure1: BMI levels according to bedtime and TV viewing tertiles. 


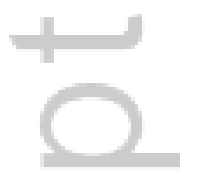




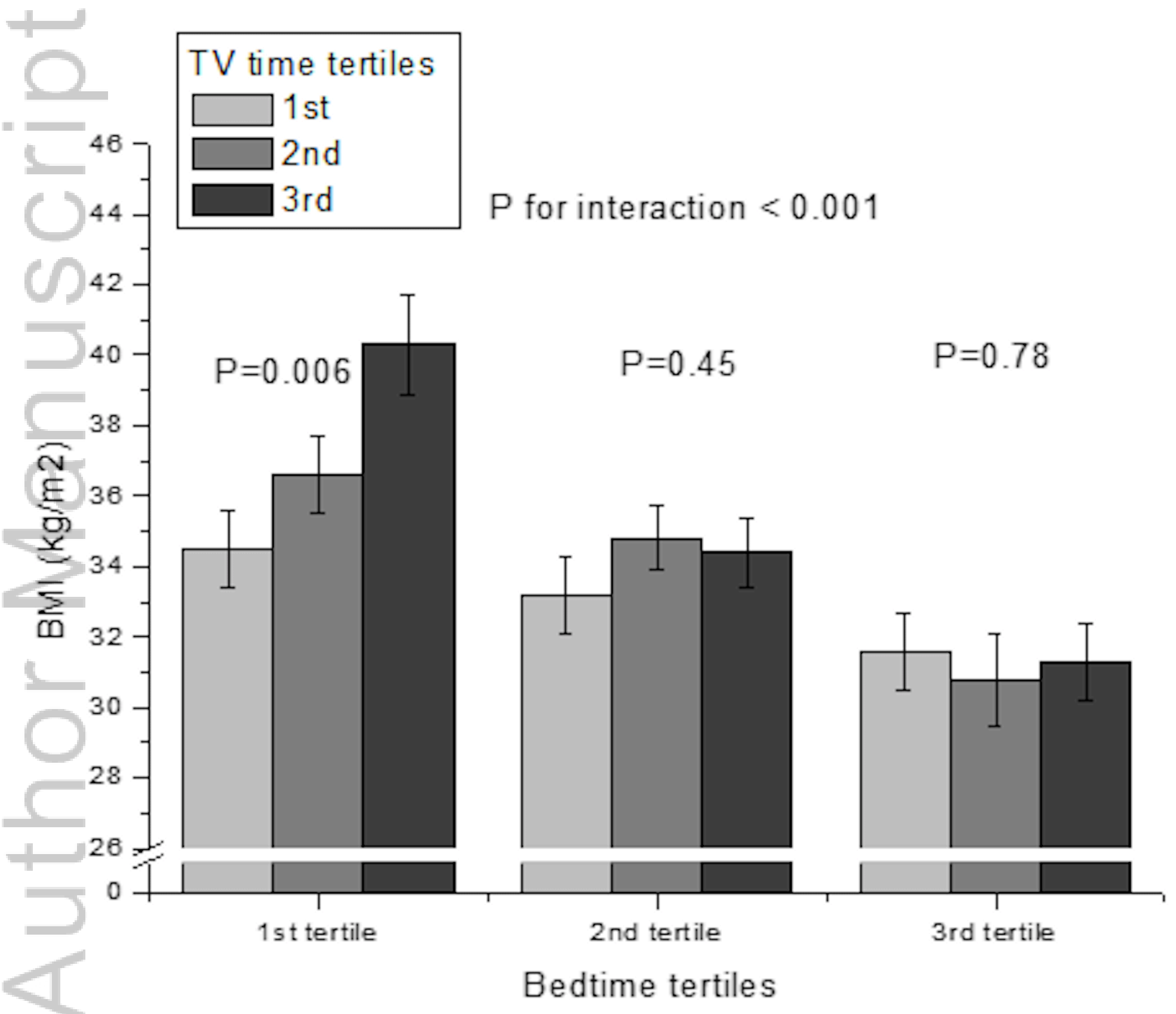

JPC_14711_Figure.tiff 


\section{Title Page, original article}

\section{Time spent watching television impacts on BMI in youth with obesity, but only in those with shortest sleep duration.}

Daniel M Golshevsky (FRACP) ${ }^{1,2}$, Costan Magnussen (PhD) ${ }^{4,5}$, Markus Juonala (PhD) ${ }^{3,6,7}$, Kung-Ting Kao (MBChB) $)^{1,2,3}$, Brooke E Harcourt ${ }^{1,2,3}$, Matthew A Sabin $(\mathrm{PhD})^{1,2,3}$

${ }^{1}$ Royal Children's Hospital, Victoria, Australia; ${ }^{2}$ University of Melbourne, Victoria, Australia; ${ }^{3}$ Murdoch Childrens Research Institute, Victoria, Australia; ${ }^{4}$ Menzies Institute for Medical Research, University of Tasmania, Hobart, Australia; ${ }^{5}$ Research Centre of Applied and Preventive Cardiovascular Medicine, University of Turku, Turku, Finland; ${ }^{6}$ Department of Medicine, University of Turku, Finland; ${ }^{7}$ Division of Medicine, Turku University Central Hospital, Finland.

Keywords: overweight, obesity, childhood, screen time, sleep, physical activity, exercise, diet

Disclosure Statement: This was not an industry supported study. The authors have indicated no conflicts of interest. Written informed consent was obtained from all participants for data collection. The study has institutional ethics approval.

Running Title: TV and sleep in youth with obesity.

Corresponding author: A/Prof Matthew Sabin, Centre for Hormone Research, Murdoch Childrens Research Institute, Flemington Road, Parkville, Victoria 3052, Australia. Tel: + 6139345 5951. Fax: +61 39345 6240. E-mail: matthew.sabin@mcri.edu.au

Acknowledgements: The authors sincerely thank the parents and children participating in the COBRA study, as well as the research team that continue to grow the COBRA repository. MJ was funded by Paulo Foundation, Paavo Nurmi Foundation, Finnish Cardiovascular Research Foundation, Finnish Medical Foundation, Maud Kuistila Foundation, Sigrid Juselius Foundation and Federal Research grants to Turku University Hospital. 


\section{University Library}

\section{- M M N E R VA A gateway to Melbourne's research publications}

Minerva Access is the Institutional Repository of The University of Melbourne

Author/s:

Golshevsky, DM;Magnussen, C;Juonala, M;Kao, K-T;Harcourt, BE;Sabin, MA

Title:

Time spent watching television impacts on body mass index in youth with obesity, but only in those with shortest sleep duration

Date:

2019-12-10

Citation:

Golshevsky, D. M., Magnussen, C., Juonala, M., Kao, K. -T., Harcourt, B. E. \& Sabin, M. A. (2019). Time spent watching television impacts on body mass index in youth with obesity, but only in those with shortest sleep duration. JOURNAL OF PAEDIATRICS AND CHILD HEALTH, 56 (5), pp.721-726. https://doi.org/10.1111/jpc.14711.

Persistent Link:

http://hdl.handle.net/11343/286730 